\title{
Diagnostic tests for caprine arthritis-encephalitis virus (CAEV) infection
}

\author{
Po-An Tu', 2 , Jen-Wen Shiau', Fang-Yu Lai ${ }^{2}$, Shen-Shyuan Yang ${ }^{3}$ and Pei-Hwa Wang ${ }^{2 *}$
}

'Hsinchu Branch, Livestock Research Institute, Council of Agriculture, Executive Yuan, No. 207-5, Bi-tou-mian, Wu-hoo village, Si-hoo Township, Miao-li County 36848, Taiwan

2Department of Animal Science and Technology, National Taiwan University, No. 50, Ln. 155, Sec. 3, Keelung Rd., Taipei City 10617, Taiwan. ${ }^{3}$ Hualein Animal Propagation Station, Livestock Research Institute, Council of Agriculture, No. 38, Chiang Road, Sec. 6, Chiang, Hualien 97362, Taiwan

\section{Article Info}

\section{Article Notes}

Received: July 15, 2017

Accepted: August 17, 2017

\section{*Correspondence:}

Dr. Pei-Hwa Wang, Ph.D., Department of Animal Science and Technology, National Taiwan University, No. 50, Ln. 155,

Sec. 3, Keelung Rd., Taipei City 10617, Taiwan.

Tel: +886-02-33664164; Fax: +886-02-27324070,

Email: demonwang@ntu.edu.tw

(C) 2017 Wang p. This article is distributed under the terms of the Creative Commons Attribution 4.0 International License.

\section{Keywords}

Caprine arthritis-encephalitis virus

Agar gel immunodiffusion test

Enzyme-linked immunosorbent assay

Isothermal amplification methods

Field diagnosis

Small ruminant lentiviruses

\section{ABSTRACT}

Caprine arthritis and encephalitis (CAE) is an economically important viral disease that causes chronic inflammatory disease in goats. At present, the diagnosis of caprine arthritis-encephalitis virus (CAEV) infection is usually obtained through serological testing or molecular techniques, while the serological agar gel immunodiffusion test (AGID) and enzyme-linked immunosorbent assay (ELISA) testing focus on the detection of CAEV antibodies, the PCR and isothermal amplification methods directly detect the proviral sequence of CAEV. The use of Western blot is still considered a "gold standard" in CAEV serology. The delayed seroconversion or intermittent antibodies and the genetic heterogeneity of regional virus strains affect the effectiveness of diagnosis by the serological and molecular methods, respectively. Here, we review some of the most recent developments in diagnostic methods and their use in both laboratory and field diagnosis.

\section{Introduction: What is CAEV?}

Caprine arthritis-encephalitis virus (CAEV) is one of the small ruminant lentiviruses (SRLV), viruses that belong to the genus Lentivirus of the family Retrovirdae $e^{1}$. The virus is able to infect goats and occasionally sheep and other related ruminants ${ }^{2}$. Epidemiological evidence indicates that the major transmission routes of the virus are through the ingestion of colostrum in milk from virus-infected adult goats by kids ${ }^{3}$, iatrogenic transmission, and lateral transmission through long-term close contact with infected goats ${ }^{4}$. All breeds and ages are susceptible to the virus, and once an infection occurs, it persists throughout the carrier's lifetime. Although most infected goats remain asymptomatic, the carriers continuously shed the virus into their environments, leading to more infections of naive goats. The infection of host cells involved in the immune system carries the virus throughout the body and into multiple organs, causing chronic inflammatory diseases. The disease manifestations in kid are normally CNS disease such as acute interstitial pneumonia, or leukoencephalomyelitis in kids ${ }^{5}$. Among adult animals, meanwhile, a CAEV infection may cause chronic polyarthritis and interstitial mastitis after prolonged virus incubation ${ }^{6}$. CAEV is mainly monocyte-tropic and macrophagetropic, while the expression of the viral genome depends on the maturation state of the cells. The viral transcripts are only produced when the cells mature into macrophages ${ }^{7}$. The international trade and movement of live goats and their germplasm play a major role in CAEV dissemination among large geographical regions ${ }^{8}$, 
while severe economic losses caused by CAEV infection are observed in particular in the context of intense goat husbandry, with decreases of about $10 \%-15 \%$ of milk yield in infected does being reported ${ }^{8}$. Relatedly, the milk contents produced by CAEV-infected does have been found to be significantly different from the milk contents of non-infected does ${ }^{9}$. In addition, there is a potential risk of viral dissemination through CAEV-infected semen ${ }^{10}$. Besides affecting production efficiency, the sanitary and economic impacts of CAEV infection are associated with interference in the international movement of goats and their germplasm due to sanitary restrictions imposed by countries that have regular control programs.

\section{Intermittent seroconversion of CAEV antibodies}

Goats produce anti-CAEV antibodies after CAEV infection. Seroconversion may then occur weeks to months after the time of infection. It is generally thought that following seroconversion, the level of anti-CAEV antibodies rises to a peak then declining to a lower but stable level ${ }^{11}$. However, some studies have reported some degree of intermittency in antibody levels, which could be the cause for false-negative results in serological tests ${ }^{12,13}$. In other words, some animals may present intermittent responses in serological tests, but the reasons for such fluctuations between positivity and negativity are not well understood ${ }^{14}$. Moreover, a loss of antibodies may also occur even after clinical signs appear ${ }^{15}$. The extent of this phenomenon is also variable, with some studies reporting that about $1 / 10$ or $2 / 10$ animals showed such fluctuations ${ }^{13}$. In any case, such fluctuations clearly constitute a confounding factor in the serological diagnosis of CAEV infection.

\section{Sequence-based phylogeny of CAEV}

Sequence-based phylogenetic analyses have demonstrated that CAEV is closely related to the maedivisna virus (MVV), a lentivirus often found in sheep. The CAEV and MVV share many features, and they are both considered to be SRLV. Based on their respective sequences of gag and pol genes, SRLV are divided into five phylogenetic groups (A to E), where group B includes the prototypes of goat CAEV subtypes ${ }^{16}$. The heterogeneity of viral strains is directly related to transcription errors in viral RNA caused by reverse transcriptase ${ }^{17}$. The genetic heterogeneity of regional virus strains should be taken into account when designing CAEV infection diagnosis and control strategies.

\section{Diagnostic test}

Various laboratory methods for the diagnosis of CAEV are available. These methods can be categorized as either serological or molecular techniques. The agar gel immunodiffusion test (AGID) and enzyme-linked immunosorbent assay (ELISA) testing are the two types of serological monitoring, while molecular assays include polymerase chain reaction (PCR) and isothermal amplification methods for the detection of CAEV proviral DNA. The Western Blot (WB) is less used for screening but is seen as "gold standard" test for diagnosis.

\section{AGID}

One of the tests most commonly used to diagnose CAE is the AGID tests recommended by the World Animal Health Organization (the OIE recommends both AGID and ELISA) (OIE, 2008), which is based on CAEV serology. The precipitation line in an AGID test is due to multiple interactions between antibodies present in the serum and viral epitopes derived from the cell culture ${ }^{18}$. The antigenantibody precipitation line can be seen within $24 \mathrm{~h}$, but the results should be read at 48-72 $\mathrm{h}$ in order to be sure of their stability ${ }^{19}$. The simplicity, specificity, and sensitivity of the test are considered suitable for initial use in control and screening programs. False-negative results may occur in an AGID test due to delayed seroconversion, slower antibody production, or as a result of the antibodies being at an undetectable level at an early stage of infection. Thus, the AGID test appears to have lower sensitivity compared to ELISA $^{20}$. Furthermore, milk samples cannot be used for an AGID test for CAEV infection.

\section{ELISA}

The ELISA test is another serological technique that has been recommended for regulatory purposes by the OIE since $2008^{21}$. Broadly, these methods can be categorized into assays that use whole virus, recombinant proteins (or synthetic peptides) as antigens, or competitive ELISAs based on the use of anti-viral monoclonal antibodies. Whole-virus MVV ELISA exhibited a sensitivity of $98.6 \%$ and a specificity of $99.3 \%$ relative to 678 sheep reference sera determined by Western Blot (WB) and recombinant gag ELISA $^{22}$. Indirect ELISAs based on recombinant or peptide antigens including recombinant p55 gag ${ }^{23}$, p25, p16, p14 core proteins ${ }^{24}$, gp46 transmembrane protein ${ }^{25}$, or purified gp135 envelope protein ${ }^{14}$ have been described. Synthetic peptides derived from $\mathrm{p} 25$ or TM have also been used. The results suggest that whole virus ELISAs tend to be more sensitive than single recombinant ELISAs. Inclusion of both a core antigen and an envelope antigen inclusion in the assay are possible to reach equivalent sensitivities and specificities to that of whole virus ELISAs. For competitive ELISA, Herrmann et al. (2003) ${ }^{26}$ described an assay based on CAEV-63 captured by one monoclonal antibody and measuring the displacement of another monoclonal antibody by test serum samples. The sensitivity and specificity of the ELISA relative to radio immunoprecipitation was determined to be $100 \%$ and $96.4 \%$, respectively, relative to RIPA.

In most countries, the routine laboratory diagnosis of 
CAEV infection is based on ELISA testing ${ }^{27}$. Such testing uses recombinant envelope glycoprotein subunits as antigens, and ELISAs have proven to be more sensitive than AGID ${ }^{25}$. Furthermore, serological analysis by ELISA can use samples other than serum, such as milk or milk whey samples ${ }^{28}$. The use of milk samples is more advantageous since collection of milk material is considered non-invasive. This approach also reduces exam costs and facilitates sample collection. The serum generally requires a dilution from 1:10 to 1:100 when performing ELISA tests to minimize the background signal. However, such dilution increases the number of false-negative results, especially in the case of a weaklypositive sample serum ${ }^{18}$. Also, as with other serological tests for CAEV infection, delayed seroconversion or intermittency in antibody levels may cause false-negative and ambiguous results in ELISA tests ${ }^{13,14}$. The phylogenetic variability of SRLV affects the results of ELISA. It was shown that the use of antigens derived from phylogenetically different viruses generates false negative results ${ }^{29}$. Thus, in a diagnostic setting the combination of at least these two subtype-specific peptides is necessary to cover a wide range of infections $s^{30}$.

\section{PCR}

Infections caused by CAEV persist due to the integration of proviral DNA into the cellular genome followed by replication in cells of the immune system. Thus, molecular biology techniques such as PCR can be used to detect the presence of the CAEV provirus. This capability has facilitated the diagnostic procedure. The different PCRbased diagnostic techniques vary according to their targets and include, for example, reverse transcription PCR for the detection of viral $\mathrm{RNA}^{31}$, as well as double-nested $\mathrm{PCR}^{32}$, semi-nested $\mathrm{PCR}^{33}$, nested $\mathrm{PCR}^{15}$, real-time $\mathrm{PCR}^{4}$, and TaqMan-based $\mathrm{qPCR}^{34}$ for the detection of viral DNA. The real-time PCR diagnostic methods have been found to provide earlier positive detection results $(\sim 15$ days postinfection) than the traditional serological AGID and ELISA methods ( $\sim 40-60$ days post-infection $)^{4}$, indicating the higher sensitivity of the former methods. The two main difficulties in developing suitable PCR tests for CAEV are strain sequence variation ${ }^{16}$ and low virus loads in vivo. Since only around $1 \times 10^{6}$ leukocytes are virus-infected ${ }^{35}$, PCR assays may produce false negative results simply because a virus load is too low to detect. Also, sophisticated thermal cyclers are required for all these PCR-based methods, with some methods requiring identification by agarose electrophoresis or by the capillary sequencing method ${ }^{36}$, further restricting the application of the methods for onsite diagnosis on farms.

\section{Isothermal amplification methods}

Several isothermal amplification methods have been developed into useful technology in the past decade. Huang et al. (2012) $)^{37}$ and Balbin et al. (2014) ${ }^{38}$ used LAMP for the rapid detection of CAEV proviral DNA. This method utilized a Bst DNA polymerase with strand displacement activity along with two outer primers (F3 and B3) and two inner primers (FIP and BIP) that recognize six specific regions within the target CAEV sequence; additional Loop-F and Loop-R primers were employed in the reaction to accelerate the LAMP amplification. However, the high variability of retroviruses (and RNA viruses) has its basis in the lack of elaborate proofreading and repair mechanisms during some (or all) of the steps in the replication of the given viral genome ${ }^{11}$. Therefore, the highly mutagenic property of proviral sequences in different CAEV strains makes designing multiple primers for use with the LAMP detection method difficult without specific software. Tu et al. $(2017)^{39}$ developed the recombinase polymerase amplification lateral flow dipstick (RPA-LFD) method for the field diagnosis of CAEV infection. Under the optimal incubation conditions, specifically, $30 \mathrm{~min}$ at $37{ }^{\text {घC }}$ for RPA followed by $5 \mathrm{~min}$ at room temperature for LFD, this assay was found to be sensitive to a lower limit of $80 \mathrm{pg}$ of total DNA and 10 copies of plasmid DNA. The RPA method applied similar primer design principles as traditional PCRbased methods, and the RPA-LFD method used the LF probe to allow for specific amplification only. The single-strand binding protein GP32 contained in the RPA mixture can enhance the nucleic acid detection limit ${ }^{40}$. The isothermal feature also makes these methods more applicable for onsite utilization at farms for both eradication programs and epidemiological studies.

\section{Western blot (WB)}

Western blot is often used as "gold standard" tests for SRLV diagnosis. However, the complex and time-consuming procedures makes WB less suitable for regular screening. The specificity is represented by visual band confirmation of the correct molecular weight. For the sensitivity of WB, researchers have shown the $\mathrm{WB}$ is either equally sensitive or more sensitive than ELISA ${ }^{41-43}$.

\section{Conclusions}

CAE is a chronic disease which causes significant losses in goat breeding. Due to delayed seroconversion or intermittent antibodies and the genetic heterogeneity of regional virus strains, the actual state of animal infection with CAEV is difficult for both serological or molecular diagnostic tests to determine with certainty. There are also other factors which affect the effectiveness of the selected technique, including the availability of commercial reagents, personnel training, the antigen/primer used, and the cost of the technique. It is clear that ELISA is generally more sensitive than the AGID test for the detection of CAEV antibodies, while molecular techniques like PCR and isothermal amplification methods appear to be more 
suitable to detect infected animals prior to seroconversion. Currently, there is still no gold standard method for CAEV diagnosis. However, by combining the advantages of both serological and molecular techniques, it might be possible to create the optimal detection method for CAEV infection.

\section{Acknowledgements}

The following are institutions that support our scientific research: National Taiwan University and Council of Agriculture, Executive Yuan (Grant No.: 106 AS-19.5.1-ST-aI).

\section{Conflict of Interest}

The authors do not have any conflicts of interest with work described in this manuscript.

\section{References}

1. Cheevers WP, Roberson S, Klevjer-Anderson P, et al.. Characterization of caprine arthritis-encephalitis virus - A retrovirus of goats. Arch Virol. 1981; 67: 111-117.

2. Reina R, Mora MI, Glaria I, et al. Molecular characterization and phylogenetic study of Maedi Visna and Caprine Arthritis Encephalitis viral sequences in sheep and goats from Spain. Virus Res. 2006; 121: 189-198.

3. Rowe JD, East NE. Risk factors for transmission and methods for control of caprine arthritis-encephalitis virus infection. Vet Clin North Am Food Anim Pract. 1997; 13: 35-53.

4. Brajon G, Mandas D, Liciardi M, et al. Development and field testing of a real-time PCR assay for caprine arthritis-encephalitis-virus (CAEV). Open Virol J. 2012; 6: 82-90.

5. Ponti W, Paape M, Bronzo V, et al. Phenotypic alteration of blood and milk leukocytes in goats naturally infected with caprine arthritisencephalitis virus (CAEV). Small Rumin Res. 2008; 78: 176-180.

6. Gjerset B, Jonassen CM, Rimstad E. Natural transmission and comparative analysis of small ruminant lentiviruses in the Norwegian sheep and goat populations. Virus Res. 2007; 125: 153-161.

7. Gorrell MD, Brandon MR, Sheffer D, et al. Ovine lentivirus is macrophagetropic and does not replicate productively in $\mathrm{T}$ lymphocytes. J Virol. 1992; 66: 2679-2688.

8. Peterhans E, Greenland T, Badiola J, et al. Routes of transmission and consequences of small ruminant lentiviruses (SRLVs) infection and eradication schemes. Vet Res. 2004; 35: 257-274.

9. Kaba J, Strzalkowska N, Jóźwik A, et al. Twelve-year cohort study on the influence of caprine arthritis-encephalitis virus infection on milk yield and composition. J Dairy Sci. 2012; 95: 1617-1622.

10. Andrioli A, Gouveia AMG, Martins AdeS et al. Fatores de risco na transmissão do lentivírus caprino pelo sêmen. Pesq Agropec Bras. 2006; 41: 1313-1319.

11. de Andres D, Klein D, Watt NJ, et al. Diagnostic tests for small ruminant lentiviruses. Vet Microbiol. 2005; 107: 49-62.

12. Barquero N, Gomez-Lucia E, Arjona A, et al. Evolution of specific antibodies and proviral DNA in milk of small ruminants infected by small ruminant lentivirus. Viruses. 2013; 5: 2614-2623.

13. Rimstad E, East NE, Torten M, et al. Delayed seroconversion following naturally acquired caprine arthritis-encephalitis virus infection in goats. Am J Vet Res. 1993; 54: 1858-1862.

14. Hanson J, Hydbring E, Olsson K. A long term study of goats naturally infected with caprine arthritis-encephalitis virus. Acta Vet Scand. 1996; 37: 31-39.
15. Cruz JCM, Gouveia AMG, Souza KC, et al. Caprine arthritis-encephalitis virus (CAEV) detection in semen of endangered goat breeds by nested polymerase chain reaction. Small Rumin Res. 2009; 85: 149-152.

16. Shah C, Böni J, Huder JB, et al. Phylogenetic analysis and reclassification of caprine and ovine lentiviruses based on 104 new isolates: evidence for regular sheep-to-goat transmission and worldwide propagation through livestock trade. Virology. 2004; 319: 12-26.

17. Callado AKC, Castro RS de, Teixeira MFDS. Lentivírus de pequenos ruminantes (CAEV e Maedi-Visna): revisão e perspectivas. Pesq Vet Bras. 2001; 21: 87-97.

18. Herrmann-Hoesing LM. Diagnostic assays used to control small ruminant lentiviruses. J Vet Diagn Invest. 2010; 22: 843-855.

19. Abreu SRO, Castro RS, Nascimento SA, et al. Produção de antígeno nucleoprotéico do vírus da artrite-encefalite caprina e comparação com o do vírus Maedi-Visna para utilização em teste de imunodifusão em ágar gel. Pesq Vet Bras. 1998; 18: 57-60.

20. Rodrigues AS, Brito RLL, Pinheiro RR, et al. Padronização do Elisa indireto e Western Blot para diagnóstico da artrite-encefalite caprina. Arq Bras Med Vet Zootec. 2014; 66: 417-424.

21. OIE. Manual of diagnostic tests and vaccines for terrestrial animals 2008.

22. Zanoni RG, Vogt HR, Pohl B, et al. An ELISA based on whole virus for the detection of antibodies to small-ruminant lentiviruses. Zentralblatt Veterinarmedizin Reihe B. 1994; 41: 662-669.

23. Schaller P, Vogt HR, Strasser M, et al. Seroprevalence of maedi-visna and border disease in Switzerland. Schweiz Arch Tierheilkd. 2000; 142: $145-153$.

24. Keen J, Kwang J, Rosati S. Comparison of ovine lentivirus detection by conventional and recombinant serological methods. Vet Immunol Immunopathol. 1995; 47: 295-309.

25. Saman E, Van Eynde G, Lujan L, et al. A new sensitive serological assay for detection of lentivirus infections in small ruminants. Clin Diagn Lab Immunol. 1999; 6: 734-740.

26. Herrmann LM, Cheevers WP, McGuire TC, et al. Competitive-inhibition enzyme-linked immunosorbent assay for detection of serum antibodies to caprine arthritis-encephalitis virus: Diagnostic tool for successful eradication. Clin Diagn Lab Immunol. 2003; 10: 267-271.

27. Chang CC, Wu SY. Comparsion of ELISA and nested PCR assays for detection of Caprine arthritis encephalitis . Taiwan Livest Res. 2016; 49: 42-49.

28. Plaza M, Sánchez A, Corrales JC, et al, Contreras A. Caprine arthritis encephalitis virus diagnosed by ELISA in lactating goats using milk samples. Small Rumin Res. 2009; 81: 189-192.

29. Grego E, Profiti M, Giammarioli M, et al. Genetic heterogeneity of small ruminant lentiviruses involves immunodominant epitope of capsid antigen and affects sensitivity of single-strain-based immunoassay. Clin Vaccin Immunol. 2002; 9: 828-832.

30. Cardinaux L, Zahno ML, Deubelbeiss M, et al. Virological and phylogenetic characterization of attenuated small ruminant lentivirus isolates eluding efficient serological detection. Vet Microbiol. 2013; 162: 572-581.

31. Leroux C, Lerondelle C, Chastang J, et al. RT-PCR detection of lentiviruses in milk or mammary secretions of sheep or goats from infected flocks. Vet Res. 1997; 28:115-121.

32. Barlough J, East N, Rowe JD, et al. Double-nested polymerase chain reaction for detection of caprine arthritis-encephalitis virus proviral DNA in blood, milk, and tissues of infected goats. J Virol Methods. 1994; 50: 101-103.

33. Eltahir YM, Dovas CI, Papanastassopoulou M, et al. Development of a semi-nested PCR using degenerate primers for the generic detection 
of small ruminant lentivirus proviral DNA. J Virol. Methods 2006; 135:240-246.

34. Li Y, Zhou F, Li X, Wang J, et al. Development of TaqMan-based qPCR method for detection of caprine arthritis-encephalitis virus (CAEV) infection. Arch Virol. 2013; 158: 2135-2141.

35. Haase AT. Pathogenesis of lentivirus infections. Nature. 1986; 322:130-136.

36. Kaba J, Rola M, Materniak M, et al. Isolation and characterization of caprine arthritis encephalitis virus in goats from Poland. Polish J Vet Sci. 2009; 12: 183-188.

37. Huang J, Sun Y, Liu Y, et al. Development of a loop-mediated isothermal amplification method for rapid detection of caprine arthritisencephalitis virus proviral DNA. Arch Virol. 2012; 157: 1463-1469.

38. Balbin MM, Belotindos LP, Abes NS, et al. Caprine arthritis encephalitis virus detection in blood by loop-mediated isothermal amplification
(LAMP) assay targeting the proviral gag region. Diagn Microbiol Infect Dis. $2014 ; 79:$ 37-42.

39. Tu PA, Shiu JS, Lee SH, et al. Development of a recombinase polymerase amplification lateral flow dipstick (RPA-LFD) for the field diagnosis of caprine arthritis-encephalitis virus (CAEV) infection. J Virol Methods. 2017; 243: 98-104.

40. Weidmann M, Rudaz V, Nunes MRT, et al. Rapid detection of human pathogenic orthobunyaviruses. J Clin Microbiol. 2003; 41: 3299-3305.

41. Zanoni R, Krieg A, Peterhans E. Detection of antibodies to caprine arthritis-encephalitis virus by protein G enzyme-linked immunosorbent assay and immunoblotting. J Clin Microbiol. 1989; 27: 580-582.

42. Brodie SJ, Pearson LD, Snowder GD, et al. Host-virus interaction as defined by amplification of viral DNA and serology in lentivirusinfected sheep. Arch Virol. 1993; 130: 413-428.

43. Houwers DJ, Nauta IM. Immunoblot analysis of the antibody response to ovine lentivirus infections. Vet. Microbiol. 1989; 19: 127-139. 